\title{
Air Quality Deterioration of Urban Areas Caused by Wildfires in a Natural Reservoir Forest of Mexico
}

\author{
Noel Carbajal, ${ }^{1}$ Luis F. Pineda-Martinez, ${ }^{2}$ and Flor Bautista Vicente ${ }^{1}$ \\ ${ }^{1}$ Instituto Potosino de Investigación Científica y Tecnológica A.C., 78216 San Luis Potosí, SLP, Mexico \\ ${ }^{2}$ Unidad de Ciencias de la Tierra, Universidad Autónoma de Zacatecas, 98600 Zacatecas, ZAC, Mexico \\ Correspondence should be addressed to Noel Carbajal; noelc@ipicyt.edu.mx
}

Received 15 December 2014; Revised 20 March 2015; Accepted 1 May 2015

Academic Editor: Richard Leaitch

Copyright (C) 2015 Noel Carbajal et al. This is an open access article distributed under the Creative Commons Attribution License, which permits unrestricted use, distribution, and reproduction in any medium, provided the original work is properly cited.

Many regions of the world suffer loss of vegetation and reduced air quality due to wildfires. Studies on aerosol emissions by wildfires often discuss the negative effects of atmospheric contaminants from a regional or mesoscale perspective. The occurrence of wildfires reveals that a high percentage takes place close to large urban areas. Very high concentration of pollutants and PM10 particulate matter reach urban zones and millions of inhabitants. These events of high pollutant concentrations are seasonally recurrent. There are many large urban areas in the world that often undergo severe air deterioration due to wildfires smoke. We document the extreme impact of wildfire that occurs in the Protected Area of Flora and Fauna La Primavera located in neighborhood of Guadalajara, a large urban zone in Mexico. The simultaneous emissions of aerosols by 60 wildfires were simulated and compared with observed data. The plume generated by the wildfires reached large areas of the central part of Mexico. The principal characteristics of smog emissions $\left(\mathrm{CO}, \mathrm{NO}_{2}\right.$, and $\left.\mathrm{PM} 10\right)$ over the urban area were acceptably reproduced. Observed and modeled $\mathrm{CO}, \mathrm{PM}_{10}$, and $\mathrm{NO}_{2}$ data indicated that aerosol plumes generated by the wildfires increased notably the concentrations over the metropolitan zone of Guadalajara.

\section{Introduction}

Wildfires emit huge amounts of gaseous and particulate matter into the atmosphere. These pollutants play an important role in the atmospheric chemistry and contribute to climate change [1-4]. Massive aerosol emissions by wildfires often threaten health and life of many people. Thick plumes of aerosols, produced by episodic wildfires, affect large urban areas and cause severe deterioration of air quality [5-8]. It is estimated that millions of tons of pollutants is emitted to the atmosphere in this kind of events [9]. Maps on the incidence of wildfires embrace a large part of the world's geography [9]. The populations of many places, like the State of California (USA), Australia, Brazil, China, Russia, and Mexico among others countries, are accustomed to experience every year the danger of wildfires in their proximity [10-14]. Wildfires events may cause catastrophic disturbances like that documented for the State of California [10]. They found that fires emitted massive quantities of aerosols to the atmosphere in October 2003 in Southern California. The wildfires devastated approximately 235000 ha of shrubs with approximately 5 million tons of pollutants emitted to the atmosphere. The incidence of forest fires represents a severe problem for Greece during the summertime. Estimations, applying the mesoscale air quality modeling system UAMAERO, indicated that forest fires were a major contributor to air pollution in tens of kilometers by deteriorating the health conditions due to an increase of the concentration of PM10 in regions around the burnt area, especially in the downwind direction from the source [5]. From 2000 to 2005 about 95000 forest fires occurred annually on average in 23 countries of Europe. It represented a burning area of about 600000 ha every year [3]. Wildfires have coexisted closely with human activities in Europe, particularly in the Mediterranean region where fires have been always present as a natural phenomenon and as a tool for grazing, agriculture, and other uses. Nowadays, the calculation of the enormous quantity of emitted pollutants to large urban zones reveals a critical problem: fires in 23 European countries caused yearly emission ranging from 8.4 to $20.4 \mathrm{Tg}$ of $\mathrm{CO}_{2}$ [4]. 
Wildfires are a global environmental problem. Applying the Carnegie-Ames-Stanford-Approach (CASA) biogeochemical model and improved satellite-derived evaluation of burned areas, van der Werf et al. [9] estimated global fire carbon emissions from the Global Fire Emissions Database (GFED3). The estimated interannual variability ranged from 1.6 Pg in 2001 to $2.8 \mathrm{Pg}$ in 1998 of $\mathrm{C} \mathrm{year}^{-1}$. If an average value of $2.0 \mathrm{Pg}$ is used, and considering a homogeneous distribution in the troposphere, it would represent a concentration of about $0.0004 \mathrm{~g} \mathrm{~m}^{-3}$ [9]. The intensity and severity of wildfires vary according to the burned vegetation and ecosystem types. Levine [1] indicates that biomass from forest, savanna, tropical forest, temperate forest, and land for agriculture is often burned by wildfires. Many of them are close to urban zones. Fire is also part of cultural practices of numerous societies to increase agriculture production and to create new land for agriculture and human settlements that the growing demographics require $[15,16]$. The massive utilization of fires for agriculture practices, land use change, and a growing population has led to a situation where about $90 \%$ of forest fires are of anthropogenic origin; that is, fire and urban zones are closely interrelated. The enormous increment of the human-induced fires became a global environment problem that affects a lot of ecosystems of the world [17].

Although the environmental perturbations caused by wildfires like deterioration of air quality have been documented in the past for countries like USA, Brazil, Indonesia, and Mexico and even for continents like Africa and Asia $[4,12,18]$, the number of wildfires increased on average in the last decades. The world's population has increased also dramatically and with it the nearness to wildfires. An example is Mexico City, one of most populated cities of the world, which is surrounded by mountains with thick forest and many wildfires that occur every year. As part of a research project, called MILAGRO, emissions by wildfires of $\mathrm{NO}$ (nitric oxide), $\mathrm{NO}_{2}$ (nitrogen dioxide), $\mathrm{HCN}$ (hydrogen cyanide), $\mathrm{NH}_{3}$ (ammonia), and VOC (volatile organic components) were estimated within the metropolitan area. An important finding was that fires produce between 79 and $92 \%$ of primary fine particles affecting Mexico City $[6,19]$. In Mexico, the episodic events of wildfires have increased in the last two decades reaching a number of 15000 documented fires per year with about 800000 ha of devastated areas. But the number increases notably when information on hot spots detected by satellites is considered [11]. Fires occur principally in the Western Sierra Madre, Southern Sierra Madre, and Eastern Sierra Madre and in the Yucatán Peninsula. The majority of fires are produced by anthropogenic activities and favored by climatic conditions. There is another urban area in Mexico that undergoes similar wildfires problems with strong deterioration of the air quality. The Protected Area of Flora and Fauna La Primavera (PAFFLP) in the State of Jalisco suffers recurrent events of wildfires that affect forest ecosystems and cause severe environmental problems due to large emissions of aerosols that spread over the adjacent large urban area of Guadalajara, with an approximated population of 5 million inhabitants. This region represents two floristic provinces: the Western Sierra Madre and the Trans-Mexican
Volcanic Belt with isolated mountain areas where vegetation communities of pines and oaks exist. In some parts there are also riparian vegetation and tropical deciduous forest, but the native flora consists dominantly of pines and oaks. These characteristics make La Primavera a source of important environmental services for the metropolitan zone of Guadalajara (MZG). Naturally and also developed artificially, there are areas of grassland and shrub, as a product of livestock that has been implemented in the area. From a business perspective, the woodland quality is not very good but it fulfils important functions such as soil conservation, habitat, and food for wildlife. On average, 29 wildfires occur per year in La Primavera. However, in 2005, the area was impacted by 89 wildfires with about 60 wildfires occurring simultaneously. The most devastating period was between 25 and 26 April 2005 when an area of 8478 ha of forest was burned. To evaluate the dispersion of the emitted aerosols over the urban zone, the Mesoscale Model of Fifth Generation (MM5), developed by the National Center for Atmospheric Research (NCAR) and the Pennsylvania State University (USA) and the Multiscale Climate Chemistry Model (MCCM), developed by the Fraunhofer Institute (Germany), were applied.

\section{Methodology}

2.1. Forest Area Description. La Primavera is located in the proximity of the metropolitan area of the city Guadalajara in the central western region of Mexico (Figure 1(b)). It embraces a surface of about 30500 ha of forest between the coordinates from $20^{\circ} 32^{\prime} \mathrm{N}$ to $20^{\circ} 44^{\prime} \mathrm{N}$ and from $20^{\circ} 32^{\prime} \mathrm{W}$ to $20^{\circ} 44^{\prime} \mathrm{W}$. The altitude varies between $1300 \mathrm{~m}$ and $2300 \mathrm{~m}$ above sea level (Figure 1(a)). The precipitation in the region is about $1000 \mathrm{~mm}$ with approximately 90 rainy days. The maximum and minimum annual means of temperature are $28^{\circ} \mathrm{C}$ and $14^{\circ} \mathrm{C}$, respectively. The adjacent large metropolitan area of Guadalajara embraces about $2700 \mathrm{~km}^{2}$ with an average population density of 1600 inhabitants per square kilometer. In Figure 1(b), the forest in La Primavera and the core of the metropolitan area are indicated. The red points indicate where the wildfires occurred. Figure 1(b) reveals the proximity of a large urban area with the forest of La Primavera and the corresponding incidence of an event of wildfires, a seasonal recurrent episode.

2.2. Air Quality Model. The atmospheric circulation and meteorological conditions were simulated by using the Mesoscale Model of Fifth Generation (MM5), developed by the Pennsylvania State University and the National Center for Atmospheric Research (NCAR). The MM5 is a nonhydrostatic, three-dimensional, and prognostic numerical model [20]. The sigma $(\sigma)$ coordinate is considered in the basic equations of the model to determine vertical levels. The model MM5 settings included the parameterization for convection by Grell et al. [20], the Blackadar boundary layer scheme, the radiation scheme of Dudhia [21], and the microphysics of Schultz [22]. The model was initiated with the National Center for Environmental Prediction (NCEP) final analysis data [23]. 


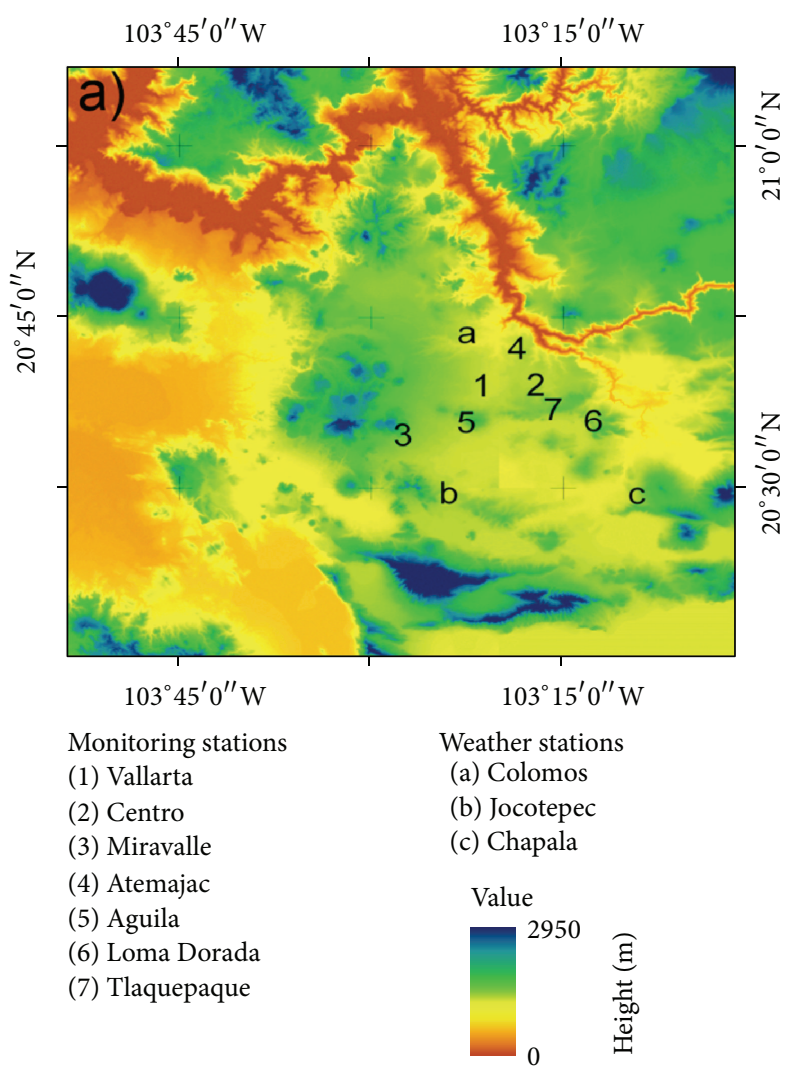

(a)

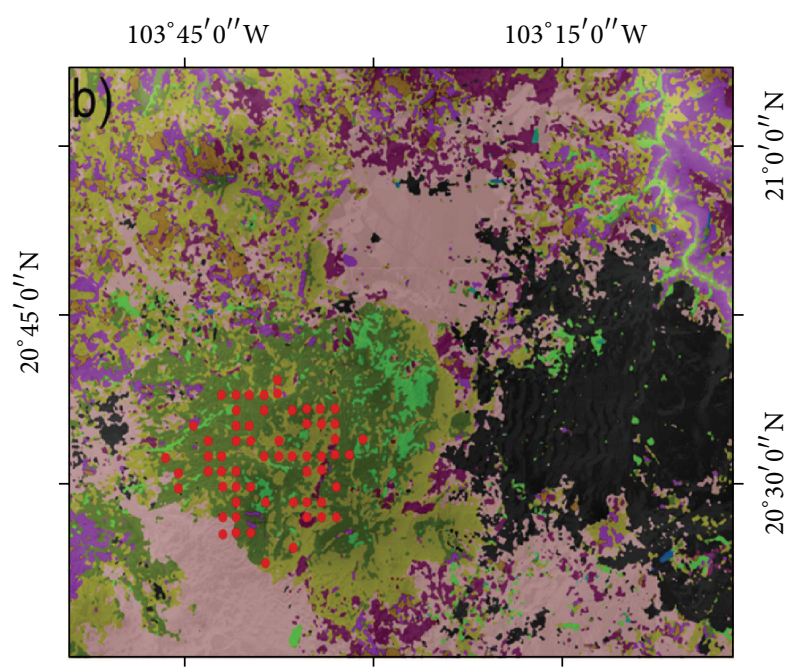

$103^{\circ} 45^{\prime} 0^{\prime \prime} \mathrm{W}$

$103^{\circ} 15^{\prime} 0^{\prime \prime} \mathrm{W}$
Xeric shrubland
Rain forest
Agriculture
Others
Urban area

(b)

Figure 1: (a) Digital Map Elevation and location of the air quality stations. (b) Land Use Map of the study area; red dots indicate hot spot identified as fires.

The distribution of gasses concentration under the prevailing meteorological conditions was simulated by using the Multiscale Climate Chemistry Model (MCCM). The MCCM is coupled with the MM5 [24]. All transport of chemical species is done online. The MCCM model includes two detailed mechanisms of the gas phase for chemical species [24]. The model simultaneously calculates the meteorological and chemical changes in the model domain and generates three-dimensional time-dependent distributions of the major inorganic and organic species. The RADM2 mechanism is widely used in atmospheric models to predict concentrations of oxidants and other air pollutants [24]. Three oneway nested domains were established at central coordinates $20.44^{\circ} \mathrm{N}$ and $103.73^{\circ} \mathrm{W}$, with a horizontal grid resolution of $9 \mathrm{~km}$ on $61 \times 61$ grid points for domain D1, $3 \mathrm{~km}$ horizontal resolution for $45 \times 45$ grid points for the second domain (D02), and $1 \mathrm{~km}$ for domain D3 in $60 \times 60$ grid, with 35 sigma vertical levels. The model was initiated with the National Centers for Environmental Prediction (NCEP) reanalysis data [23]. This dataset is based on observational and global reanalysis models data with temporal resolutions of 6 hours and 28 sigma vertical levels. The numerical simulation was initialized at 00Z 24 April 2005 with duration of 4 days and outputs every hour.
2.3. Emissions. In order to estimate the emissions of air pollutants from forest fires, it is necessary to know two fundamental aspects of this process: the type and fuel loading. The fuel charge is based on the amount of available biomass, that is, the combustible material to be consumed in a wildfire under specified weather conditions. Emissions were estimated according to the proposed methodology by Seiler and Crutzen [25] and described by Wiedinmyer et al. [26]. The emissions, for a component $i$ in a specific fire position and time known, can be estimated as

$$
\text { Emission }=A * B * \mathrm{CE} * e i,
$$

where $A$ is the burned area, $B$ is the biomass fuel loading per unit area, $\mathrm{CE}$ is the combustion efficiency, or the fraction of burned biomass, and $e i$ is an emission factor for each specific chemical species [26]. The amount of burned biomass in La Primavera between 25 and 26 April 2005 was estimated using this methodology. We consider the criterion of the total accumulated biomass without preceding historic fires events to estimate the total emissions.

The accumulated fuel charge that builds up is considered to be a criterion to approximate the load biomass burned in an area with no history of fires. For La Primavera, the following information was applied: $A=8478$ ha total burned area; 
TABLE 1

\begin{tabular}{lcc}
\hline Species name & Model emission name & Emission $\left(\mathrm{kg} / \mathrm{km}{ }^{2} / \mathrm{h}\right)$ \\
\hline Acetaldehyde & e_ald & 0.053146 \\
Carbon monoxide & e_co & 2.883972 \\
Alkanes with $\mathrm{kOH}$ & e_eth & 0.005491 \\
Alkane $2500<\mathrm{kOH}<5000$ (exclude butanes) & e_hc3 & 0.161604 \\
Alkane $5000<\mathrm{kOH}<10000$ (exclude pentanes) & e_hc5 & 0.181363 \\
Alkane $\mathrm{kOH}>10000$ & e_hc8 & 0.174374 \\
Formaldehyde & e_hcho & 0.005191 \\
Ammonia & e_nh3 & 0.000865 \\
Nitrogen Oxide & e_no & 0.063717 \\
Nitrogen Dioxide & e_no2 & 0.020831 \\
Ethylene & e_ol2 & 0.01908 \\
Alkene $\mathrm{kOH}>20000$ & e_oli & 0.021758 \\
Alkene $\mathrm{kOH}<20000$ & e_olt & 0.021927 \\
Unspeciated Primary PM10 & e_pm10 \\
Unspeciated Primary PM2.5 & e_pm2 & 0.016682 \\
Sulfur dioxide & e_so2 & 0.008337 \\
Toluene & e_tol & 0.02749 \\
Aromatic $k \mathrm{OH}>20000$ & e_xyl & 0.021457
\end{tabular}

$B=24.2$ ton/ha, average accumulated biomass reported by Carmona et al. [27]; and $\mathrm{CE}=0.25$ being the efficiency of burning vegetation, reported by Michel et al. [28] for this specific type of forest. The CE is largely dependent on fuel type, moisture content, and the conditions under which combustion takes place, such as the soil moisture or relative humidity [13]. In grassland and woodland regions, such as La Primavera, fuel moisture was taken into account for selecting the CE.

These data meant a burnt biomass of 51291.9 tons. Emission factors for each of the chemical species according to reported data by Wiedinmyer et al. [26] were applied. From this process an emission inventory is obtained. This emission inventory was introduced into the MCCM model. Previously, the grid points for the emission during the event were identified. The model was initialized with constant emissions fluxes for the major gasses and particulate matter components throughout the event. Additionally, an urban emissions inventory was included according to the methodology proposed by Pineda-Martínez et al. [29]. This also includes a background concentration plus a contribution of urban specific emissions related to industrial activity and mobile sources. With these specifications, better results were obtained in the comparison between modeled outputs concentrations and observed air quality data in the MZG. In Table 1, a list of the emissions inventories is shown.

\section{Results and Discussion}

3.1. Wildfire Event Description. Wildfires occur practically in all forest ecosystems. La Primavera forest has not been the exception in experiencing these recurrent episodes of wildfires every year. Reported data indicate that 207 fires occurred in this ecosystem during the period 1995-2004, but over 89 hot spots were reported as fires only during the spring time of
2005. This information was obtained from the National Commission for Knowledge and Use of Diversity (CONABIO) [30]. CONABIO receives data from the Moderate Resolution Imaging Spectroradiometer (MODIS) and from NOAAAVHRR (National Oceanic Atmospheric AdministrationAdvanced Very High Resolution Radiometer). Low moisture content in the atmosphere and strong winds caused the start and propagation of fires on 25 and 26 April 2005. In fact, the years 2004 and 2005 were unusually dry for this region creating potential conditions for wildfires. Specifically, during the spring of 2005 extreme drought conditions prevailed, with $0.2 \mathrm{~mm}$ rainfall for this period. Nevertheless, during the previous autumn in 2004 a precipitation event occurred that produced growth of grasses and herbaceous plants increasing the available fuel biomass. The April 2005 fires event was the most devastating for La Primavera during the past 10 years with a total burned area of 8,478 ha.

3.2. Model Validation. Several numerical experiments were carried out to improve the agreement between calculated and observed data. It is of fundamental importance to reproduce conditions of temperature, wind conditions, and humidity to model correctly the plume of the produced aerosols. In Figure 1(b), the position of 60 wildfires which occurred simultaneously is showed. Although a total number of 89 wildfires were detected, about 29 were of much minor scale. In Figure 2, time series for the studied period of modeled and observed data of temperature, relative humidity, and wind speed are compared for three different positions in the urban zone of Guadalajara which are Colomos, Jocotepec, and Chapala. These three points were selected so that completely separated zones were monitored. In the northern part of the urban area at Colomos (Figure 1(a)), the agreement between observed and modeled temperature data is acceptable with 

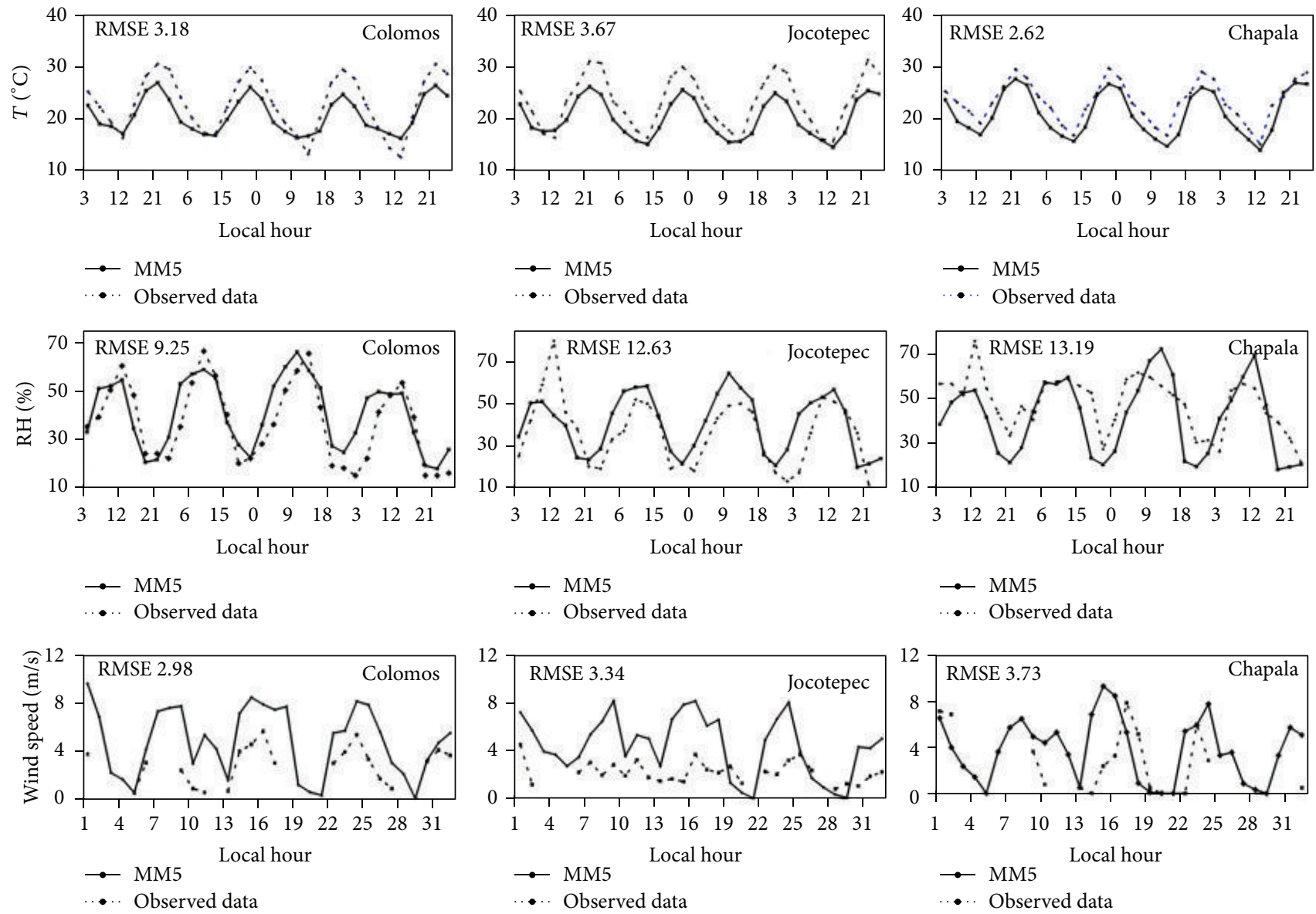

FIGURE 2: Comparison of measured and calculated meteorological variables (temperature, relative humidity, and wind speed) at three different stations from 24 to 28 April 2005.

a root mean square error (RMSE) of 3.18. For the relative humidity a RMSE of 9.25 was estimated. Considering that this station is located in the urban area where buildings and street orientation are not taken into account in the calculations, the agreement (RMSE $\sim 3$ ) for the wind speed is acceptable and of the same order as in other works [29]. The meteorological station Jocotepec is located in the southern side of the urban area. For temperature and wind speed similar RMSE were obtained as for Colomos. For the relative humidity a larger RMSE of 12.6 was estimated. In the town of Chapala, the meteorological station is located close to one of the largest lakes of Mexico. Probably, the real humidity conditions were not satisfactorily considered in the model which would explain the largest difference between observed and modeled data (RMSE 13.2). It is of interest to mention that the range of variability of temperature, relative humidity, and wind speed is approximately of the same order in the three stations. The agreement of the time series of observed and modeled data at these three different positions of the urban area suggests that the meteorology of the region is satisfactorily reproduced. The dominant westerly winds were also acceptably modeled as it can be inferred from Figures 2 and 3 and from the satellite image showing an aerosol plume dispersing in the east direction (Figure 6).
3.3. Modeled Temperature and Wind Fields. To understand the behavior and the influence of wildfires it is necessary to know the distribution of temperature and wind speeds over La Primavera and over the urban area. Time series of maximum and minimum temperatures, relative humidity, wind speed, and wind direction are displayed in Figure 3 for April 2005. Temperatures above $34^{\circ} \mathrm{C}$ (Figure 3(a)) and low relative humidity of about 36\% (Figure 3(b)) prevailed over the whole month creating a very dry situation. The weather conditions during the fire were characteristic of a drought period, where an anticyclonic circulation causes clear sky and high solar radiation [31]. Once started, strong west winds were presented with gusts over $11 \mathrm{~m} / \mathrm{s}$ which enabled the rapid spread of fires on 26 April (Figures 3(c) and 3(d)).

In Figure 4, the simulated values for temperature and wind fields are depicted for the following times: 26 April at $06 \mathrm{Z}$ (Figure 3(a)), 26 April at 12Z (Figure 3(b)), 26 April at $18 \mathrm{Z}$ (Figure 3(c)), and 27 April at $00 \mathrm{Z}$ (Figure 3(d)). It can be noted that relatively warm conditions predominated with temperatures above $30^{\circ} \mathrm{C}$ and winds flowing from $\mathrm{La}$ Primavera to the MZG. Warm-dry conditions and favorable wind direction for the spread of emissions to the urban area are typical for this season of the year. During these days the wind direction remained from west to east with an intensity 


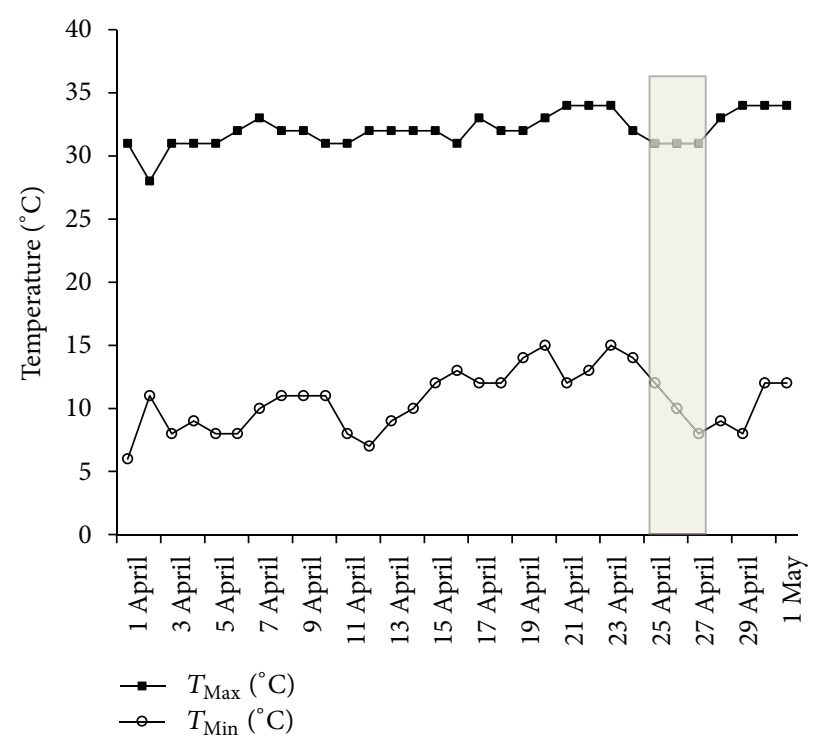

(a)

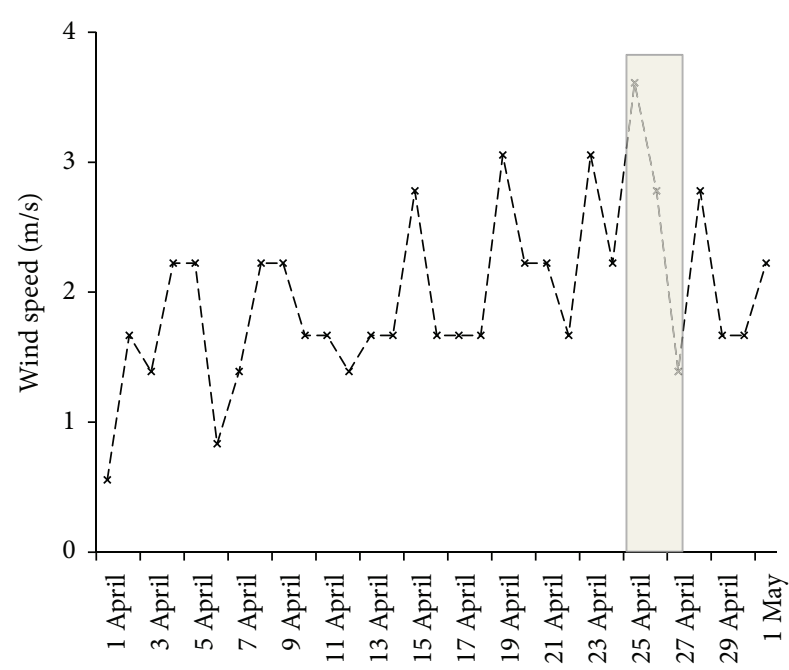

(c)

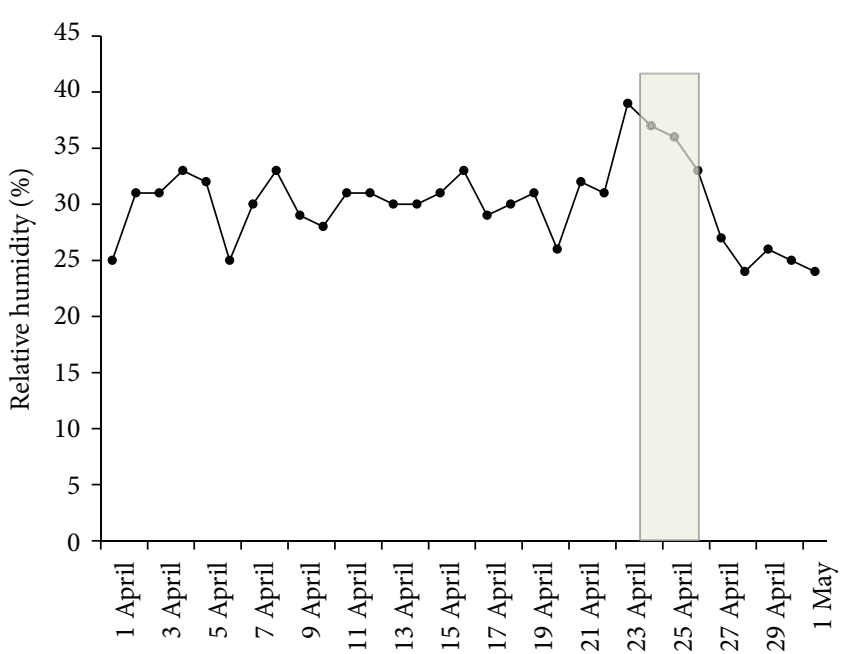

(b)

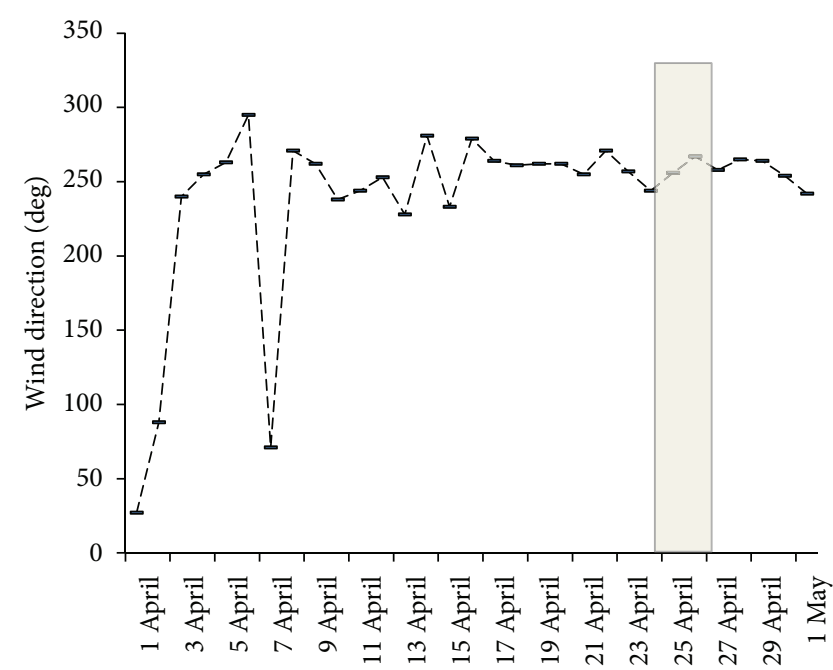

(d)

FIGURE 3: Time series of meteorological variables during the month of April 2005. Maximum and minimum temperature (a), relative humidity (b), wind speed (c), and wind direction (d). The shading indicates the critical period of wildfires.

varying between 5 and $10 \mathrm{~ms}^{-1}$. In fact, this wind pattern (direction and speed) reached areas of the central part of Mexico, that is, about $300 \mathrm{~km}$ away from Guadalajara. In Figure 4(b), the positions of La Primavera and of the urban area are indicated to show how the city of Guadalajara is exposed to aerosols emitted from the forest fires. Although in some areas the temperatures were even lower than $10^{\circ} \mathrm{C}$, the dominant temperature patterns ranged between $15^{\circ} \mathrm{C}$ at night and above $34^{\circ} \mathrm{C}$ during the day. The low atmospheric moisture, high temperatures, and wind conditions were favorable to the incidence of wildfires. The relative humidity is also an important and decisive factor for fire ignition. The average maximum of relative humidity is about $74 \%$ and it occurs during the rainy month of August, and a minimum of about $40 \%$ prevails during April. The winds show a seasonal behavior with a preferential direction from west and southwest during the cool-dry winter season from November to April and from the east and southeast direction during the warm-wet period. Relative humidity, winds, and temperature depicted in Figures 3 and 4 reflect the conditions of a strong drought period which occurred in April 2005.

3.4. Dispersions Maps. In Figure 5, the results of the dispersion process of the aerosols generated by the wildfires are shown. In the numerical modeling the presence of the adjacent urban area and its own emissions was also considered. The MCCM model also considered the emissions of urban areas. The distributions of carbon monoxide (CO), nitrogen dioxide $\left(\mathrm{NO}_{2}\right)$, and PM10 particulate matter are described at three different times: $00 \mathrm{Z}$ on 25 April, $03 \mathrm{Z}$ on 26 April, and 00Z on 27 April of 2005. In Figures 5(a), 5(b), and 5 (c) representations of the patterns of $\mathrm{CO}, \mathrm{PM10}$, and $\mathrm{NO}_{2}$ 


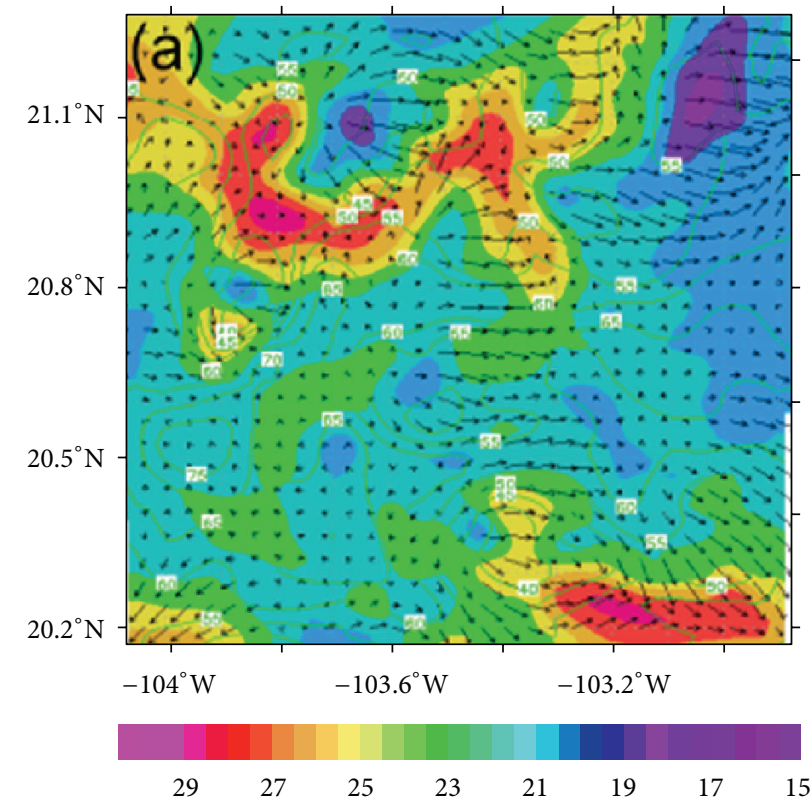

(a)

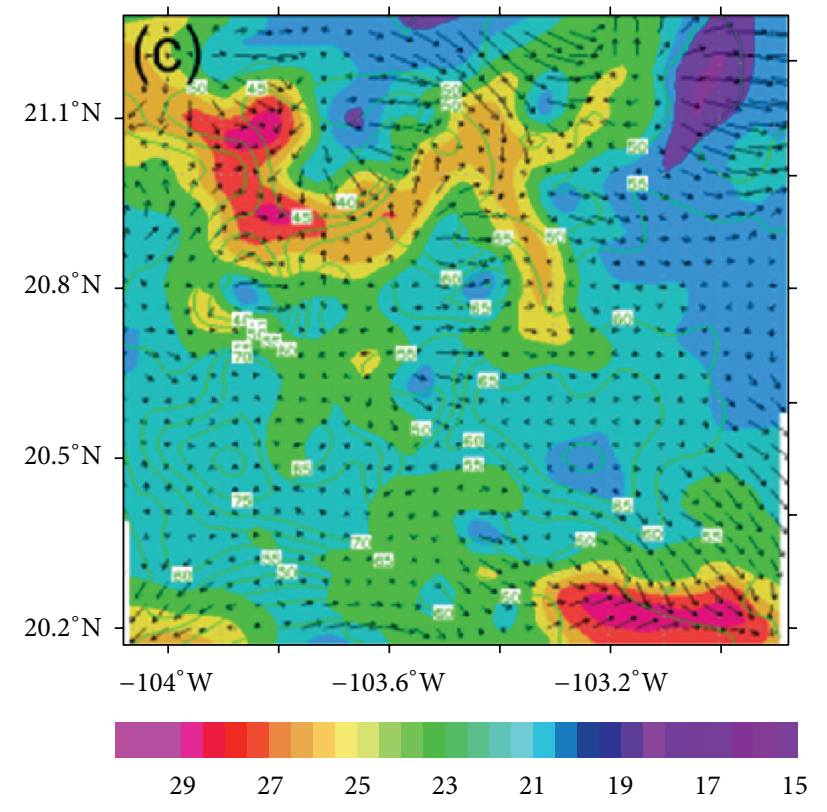

(c)

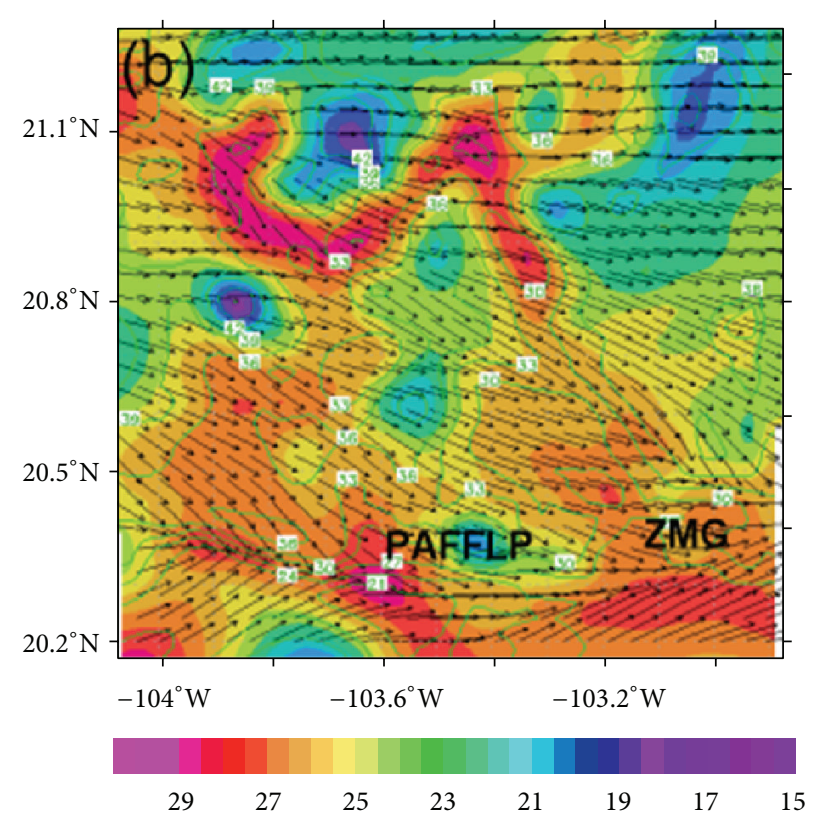

(b)

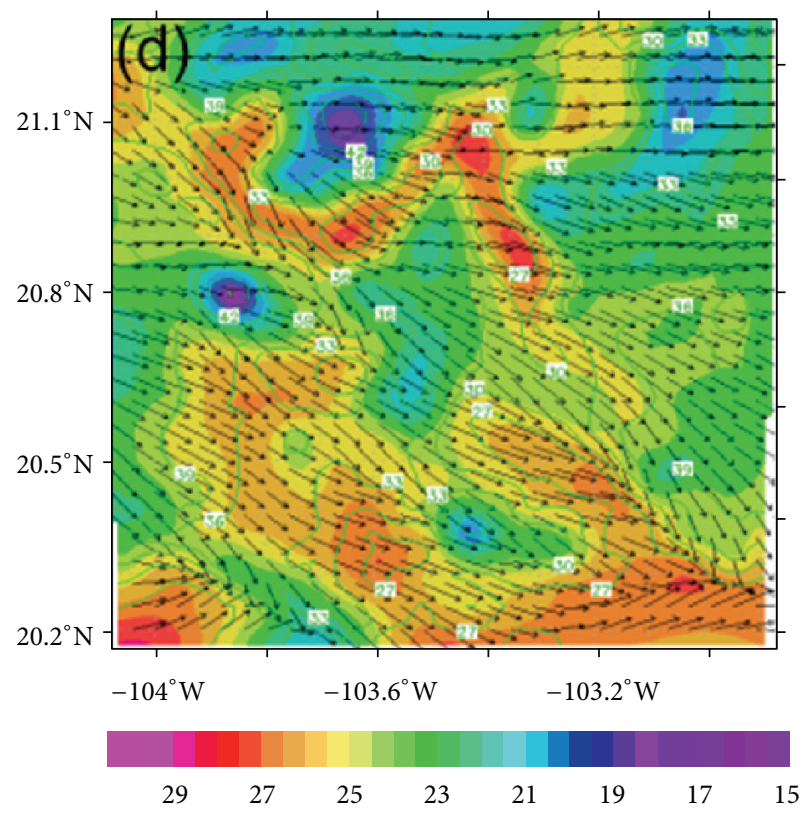

(d)

FIGURE 4: Surface temperature and winds vectors at four different times: (a) 26 April 06Z, (b) 26 April 12Z, (c) 26 April 18Z, and (d) 27 April 00Z. Observe that winds flow from La Primavera to the urban area.

at $00 \mathrm{Z}$ on 25 April are described at the time when the event of many wildfires initiated. Two separated plumes can be distinguished, one from the initial emissions of the wildfires and the other from the urban area. At this time, the emissions of $\mathrm{NO}_{2}$ and PM10 are higher in the urban area, but the CO emissions are larger in La Primavera. When the wildfires intensified (Figures 5(d), 5(e), and 5(f)), the concentrations of all three parameters (CO, PM10, and $\mathrm{NO}_{2}$ ) were definitively higher. Where the wildfires occurred ( $03 \mathrm{Z}$ on 26 April), west winds (see Figure 4) transported the pollutants towards the urban area; that is, the MZG was affected seriously with high concentrations of pollutants. This process increased notably at $00 \mathrm{Z}$ on 27 April when the plumes of CO, PM10, and $\mathrm{NO}_{2}$ involved large areas of the MZG and its surroundings with very high concentrations of pollutants affecting a consequently large number of inhabitants (Figures 5(g), $5(\mathrm{~h})$, and 5(i)). The intense winds blowing from the west transported the pollutants far away from the urban area of Guadalajara reaching areas of the central part of Mexico. The highest concentrations are located over La Primavera where 

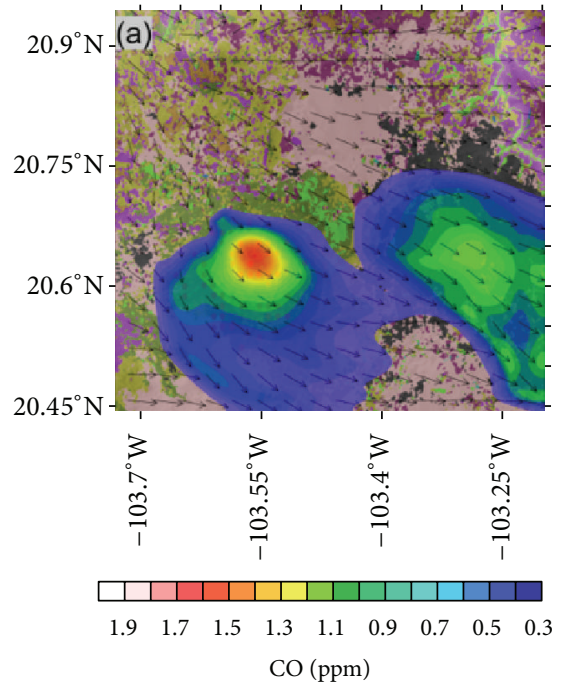

(a)

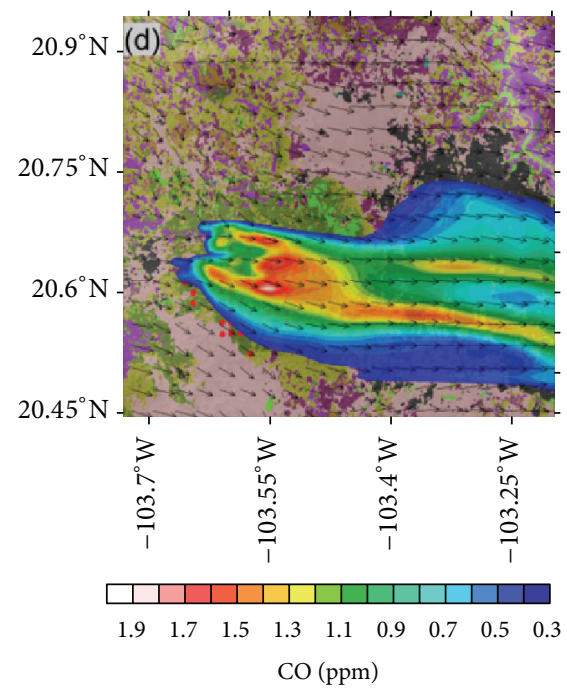

(d)

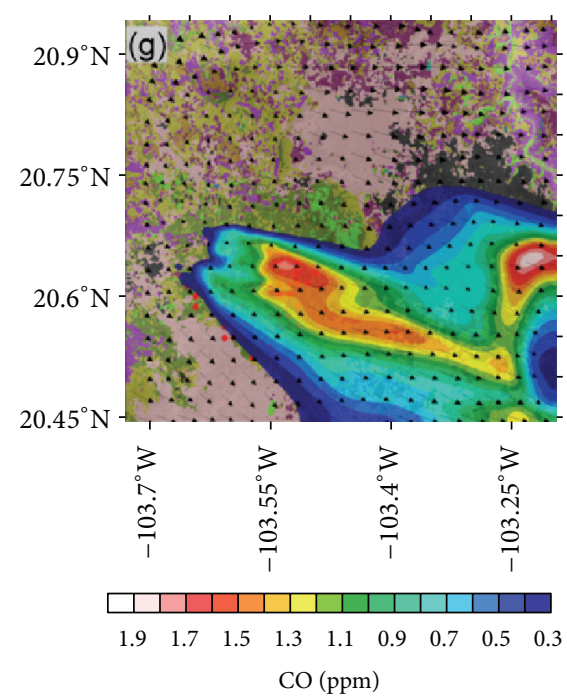

(g)

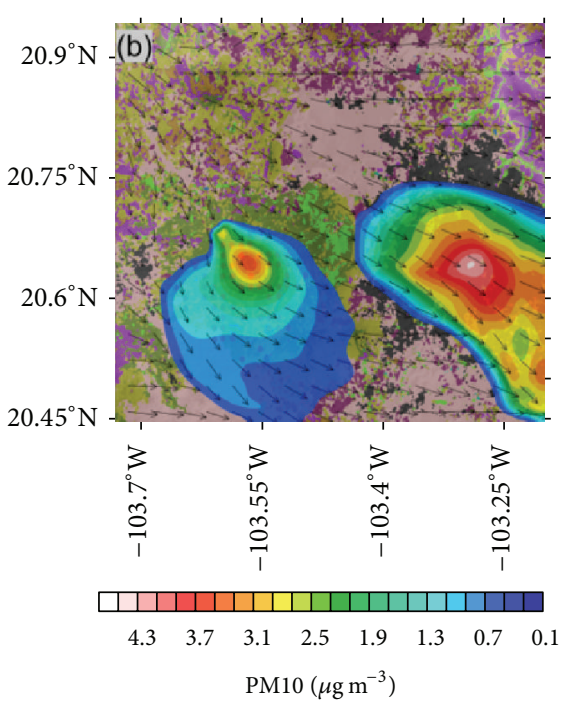

(b)

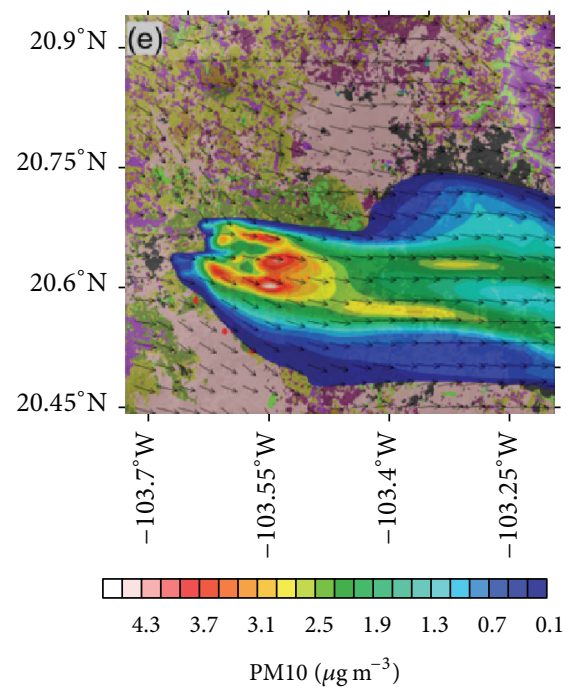

(e)

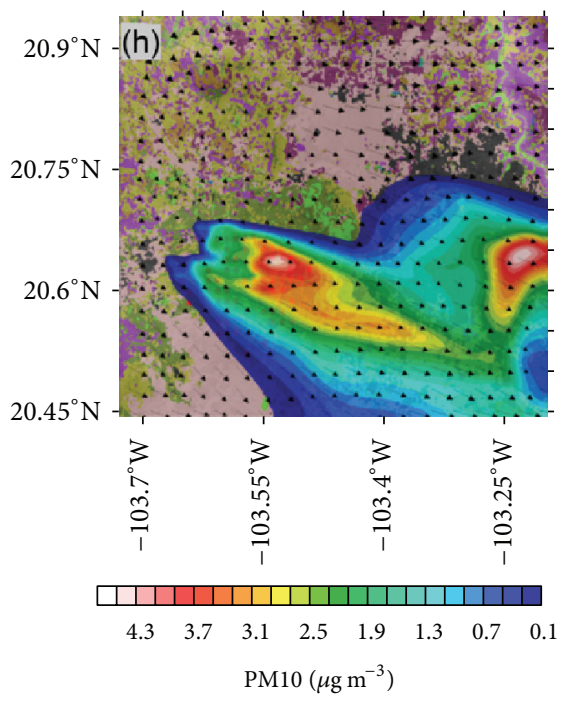

(h)

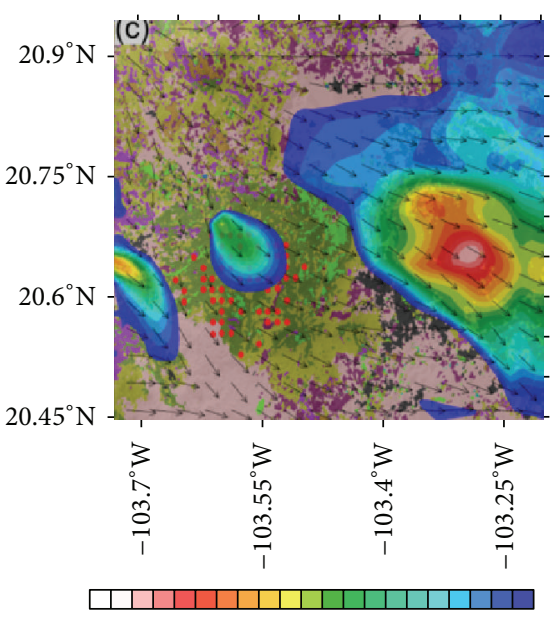

$\begin{array}{lllllll}0.021 & 0.018 & 0.015 & 0.012 & 0.009 & 0.006 & 0.003\end{array}$ $\mathrm{NO}_{2}(\mathrm{ppm})$

(c)

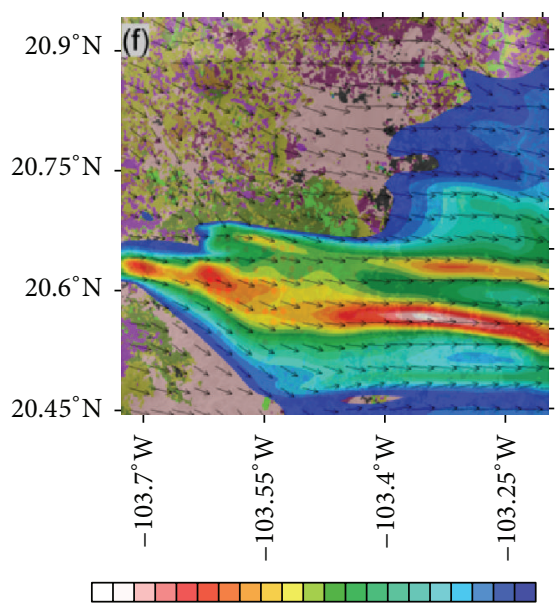

$\begin{array}{lllllll}0.021 & 0.018 & 0.015 & 0.012 & 0.009 & 0.006 & 0.003\end{array}$ $\mathrm{NO}_{2}(\mathrm{ppm})$

(f)

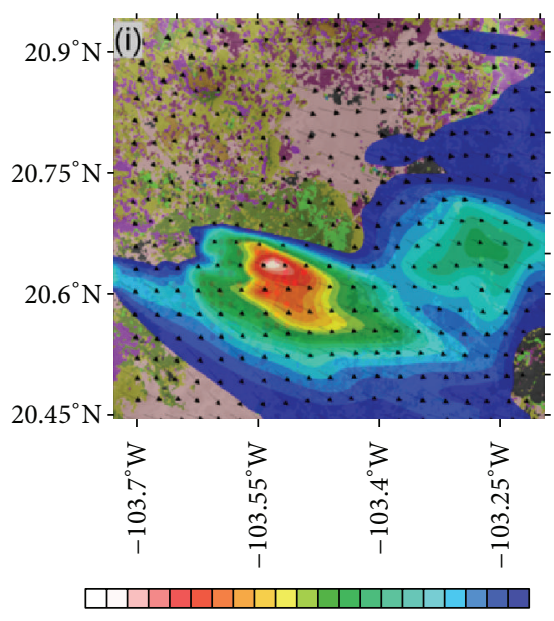

$\begin{array}{lllllll}0.021 & 0.018 & 0.015 & 0.012 & 0.009 & 0.006 & 0.003\end{array}$ $\mathrm{NO}_{2}(\mathrm{ppm})$

(i)

FIGURE 5: Maps of the calculated plumes for three of the principal components of the pollutants emitted $\left(\mathrm{CO}, \mathrm{PM}_{10}\right.$, and $\left.\mathrm{NO}_{2}\right)$ by the wildfires are displayed. The plumes are shown for three different times; at the initial period of the event of many wildfires, $00 \mathrm{Z}$ on $25 \mathrm{April}$ (a), (b) and (c), at the time of large intensity, 03Z on 26 April (d), (e) and (f), and at final time of the event, 00Z on 27 April (g), (h), and (i). 


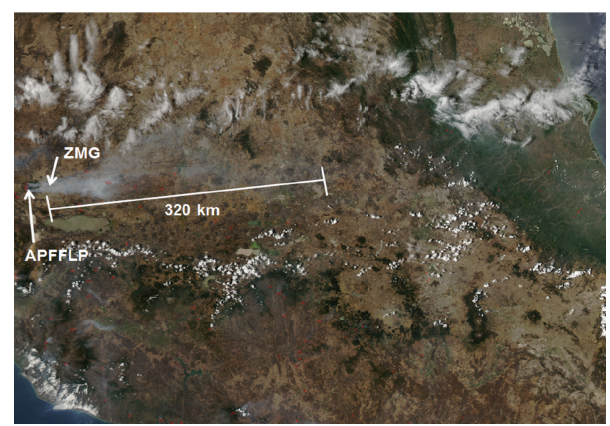

FIGURE 6: Satellite image of the central part of Mexico. The locations of La Primavera and of the metropolitan zone of Guadalajara (MZG) are indicated. The image reveals the extent of the plume generated by the wildfires in La Primavera. Satellite Aqua (NASA) [35].

the wildfires occur. The major concern about these events is the frequency and impact of plumes of pollutants spreading over the MZG every year during the dry season.

The intense winds blowing from the west transported the pollutants far away from the urban zone of Guadalajara reaching regions of the central part of Mexico. In Figure 6, a satellite image reveals the extent of the plume which reached distances of more than $300 \mathrm{~km}$ with significant aerosol concentrations. The simulated aerosol plume, depicted in Figure 5, has a similar structure as in the satellite image (Figure 6). To understand the importance of the air deterioration caused by this plume, it is convenient to mention that this plume embraces an area that includes a series of cities in the central part of Mexico that sum a few millions more of affected inhabitants.

3.5. Effects on the ZMG. In Figures 2 and 4, time series of relative humidity and calculated temperature and wind fields were described. High temperatures, a drought period, and strong winds created favorable conditions for the initiation of fires and the posterior dispersion of the plume eastwards. The model was able to capture the regional circulation and the conditions that prevailed during the fires. The dominant eastward circulation caused a strong deterioration of the air quality in MZG and in central regions of Mexico (Figure 7). The vertical wind field, showed in Figure 7, reveals the existence of convergence and divergence zones in the urban area which contribute to the observed pollutants concentration. In urban areas, converging air masses may lead to higher concentrations of pollutants and in divergence areas; that is, in areas of descending air, usually the concentrations are smaller. Another effect exists that contributes to the observed local circulation system in La Primavera and in the MZG which is generated by the differential heating between the forest and urban areas. The heat island enhances convection over the urban area $[31,32]$. This effect is detected in Figure 7, where concentrations of $\mathrm{CO}, \mathrm{PM} 10$, and $\mathrm{NO}_{2}$ are displayed for 26 April at the time when the plume disperses over the urban area. Concentrations of $\mathrm{CO}$ varied between 0.4 and $1.6 \mathrm{ppm}$, those of PM10 between 1 and $4 \mu \mathrm{g} \mathrm{m}^{-3}$, and those of $\mathrm{NO}_{2}$ between 0.004 and $0.02 \mathrm{ppm}$. Areas with rising air are marked with $(+)$ and zones with descending air are indicated with (-). The plume disperses strongly over the urban area. Once the plume was over the urban area, it caused cooling by the indirect effect of aerosols, with a temperature decrease of about $\Delta T=4^{\circ} \mathrm{C}$.

In Figure 8, the comparison between observed and calculated concentrations of $\mathrm{CO}$ and $\mathrm{NO}_{2}$ for different meteorological stations monitoring the air quality is shown. These meteorological stations belong to the metropolitan network of meteorological stations of Guadalajara [33]. It can be seen that the orders of magnitude of the concentrations are correctly modeled and that, at the time when the intensity of wildfires was a maximum (shaded zones), the model reproduced acceptably the peaks in the concentrations of $\mathrm{CO}$ and $\mathrm{NO}_{2}$. Increasing concentrations of various chemical compounds $\left(\mathrm{CO}, \mathrm{CO}_{2}\right.$, and $\left.\mathrm{NO}_{2}\right)$, emitted during the wildfires, affect not only the urban area but also all population groups adjacent to La Primavera. It is important to remark that the MZG is one of the largest urban areas in Mexico. This implies that there are underlying problems of poor air quality, in which high concentration emission of particles like $\mathrm{CO}$ and PM10 is added. Further, about $50 \%$ of primary organic carbon emission could be attributed to wood smoke and the large fraction of secondary organic carbon indicates that forest fires may strongly contribute to gas-to-particle processes [34]. Wildfires largely contribute as emission sources for the presence of such as compounds in the atmosphere.

In general, the high concentrations of $\mathrm{NO}_{2}$ in the stations Aguila, Atemajac, Tlaquepaque, and Vallarta were well reproduced. It is important to mention that $\mathrm{NO}_{2}$ is also emitted in the urban area. Although the order of magnitude of the modeled peaks of CO concentrations agrees with the observed high concentrations in the monitoring stations, there is a delay difference of a few hours. The probable reason for this is that the information about the initiation of the wildfires was not correctly documented. It is relevant to mention that the MCCM model was able to calculate a realistic plume of aerosol that extended over the metropolitan zone of Guadalajara and over large urban areas of Mexico. The plume, caused by a relative large number of wildfires, generated very high concentration in the metropolitan zone of Guadalajara that was well reproduced by the model. In fact, the concentrations of $\mathrm{NO}_{2}$ at the monitor stations Aguila and Vallarta on 24 April (see Figure 8), that is, without influence of fires, were of the order of $0.03 \mathrm{ppm}$. At the same stations, on 26 April when the influence of fires was large, the values of observed and modeled concentrations were three times larger. Observed and modeled concentrations of $\mathrm{CO}$ at the monitor stations Miravalle, Loma Dorada, and Aguila were on 26 April 3 to 4 times larger than on 24 April. The aerosol plumes generated by wildfires in La Primavera (see Figure 7) affected decidedly the urban area of Guadalajara.

\section{Conclusions}

We have documented the problem of large urban areas located in the neighborhood of a region with large incidence of wildfires. The prevailing conditions in the study region, 


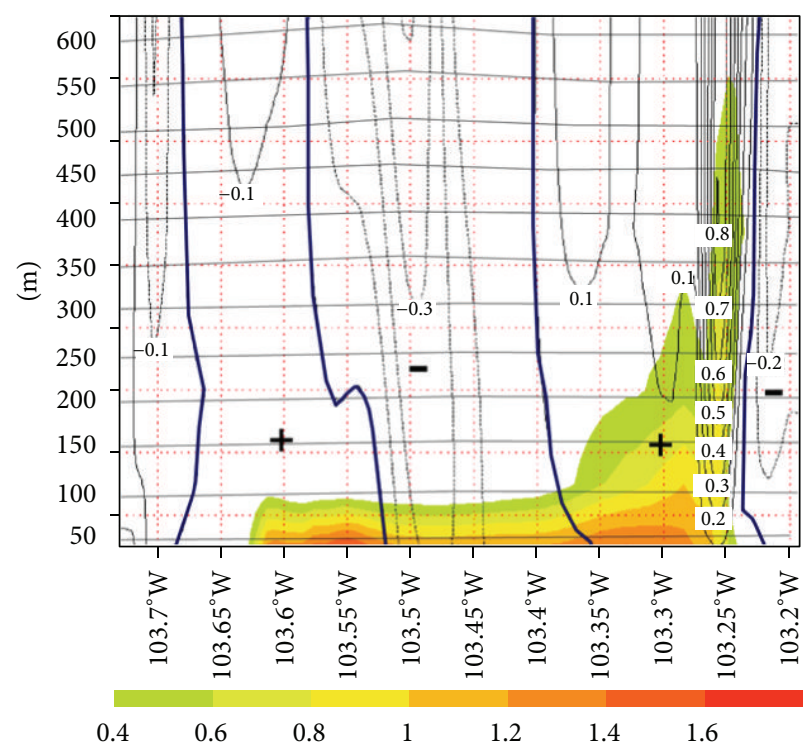

(a)

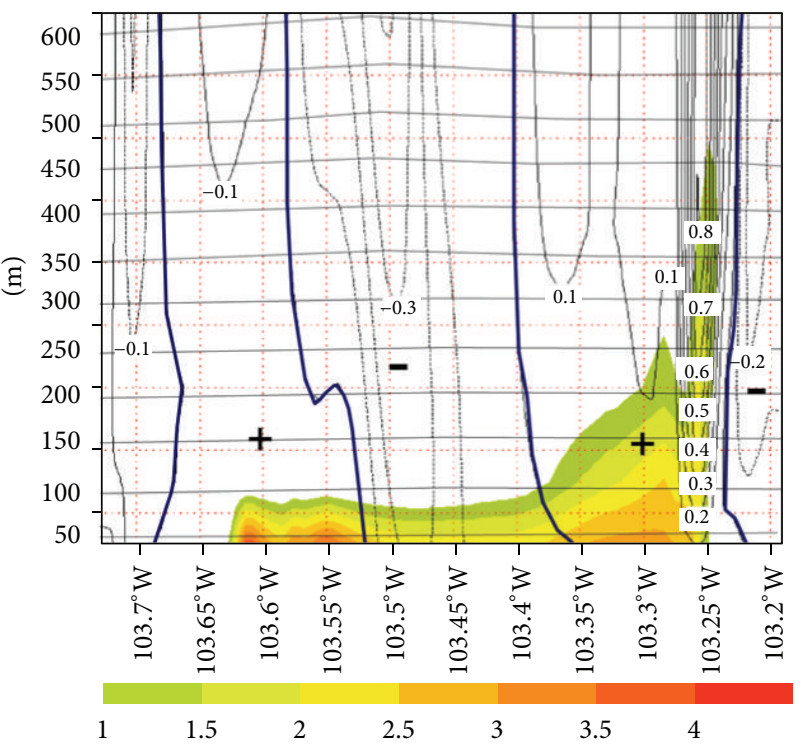

(b)

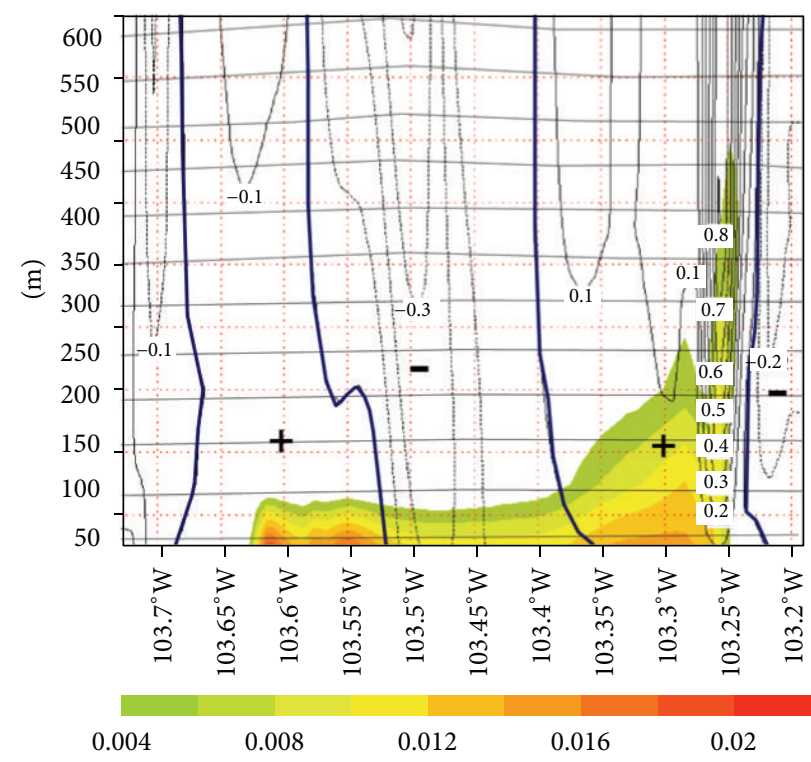

(c)

Figure 7: Cross section along the latitude $20.66^{\circ} \mathrm{N}$ (from $103.2^{\circ} \mathrm{W}$ to $103.7^{\circ} \mathrm{W}$ ), for a height of $600 \mathrm{~m}$ and conditions for 26 April with downwind from West to East; (a) $\mathrm{CO}(\mathrm{ppm}),(\mathrm{b}) \mathrm{PM} 10\left(\mu \mathrm{g} \mathrm{m}^{-3}\right)$, and (c) $\mathrm{NO}_{2}(\mathrm{ppm})$. Contours indicate the vertical wind component. Zones with rising air are indicated with $(+)$ and areas with descending air with $(-)$.

during drought periods, become a potential hazard to the air quality of the MZG. The dominant southwesterly winds during winter together with fire events in La Primavera represent an additional source of emissions for the urban area. The vegetation in La Primavera, mainly pine, oaks, and grassland, causes the fact that the fires contribute mainly with carbon primary components and with atmospheric particles. The growing population and the creation of new residential zones have reduced the distance between humans and wildfires. We have mentioned that this problem exists in many parts of the world. Although we have described the problem of La Primavera, a region adjacent to the city of Guadalajara, Mexico, we call the attention about this growing concern worldwide. It has been demonstrated that warm-dry conditions and a favorable wind direction combine to produce a flow of aerosols, emitted by the wildfires, over the large urban area of Guadalajara. It is also worth mentioning that wildfires and aerosols emissions are a recurrent phenomenon in this season of the year. The emitted aerosols by a relative large number of wildfires are transported under typical meteorological 

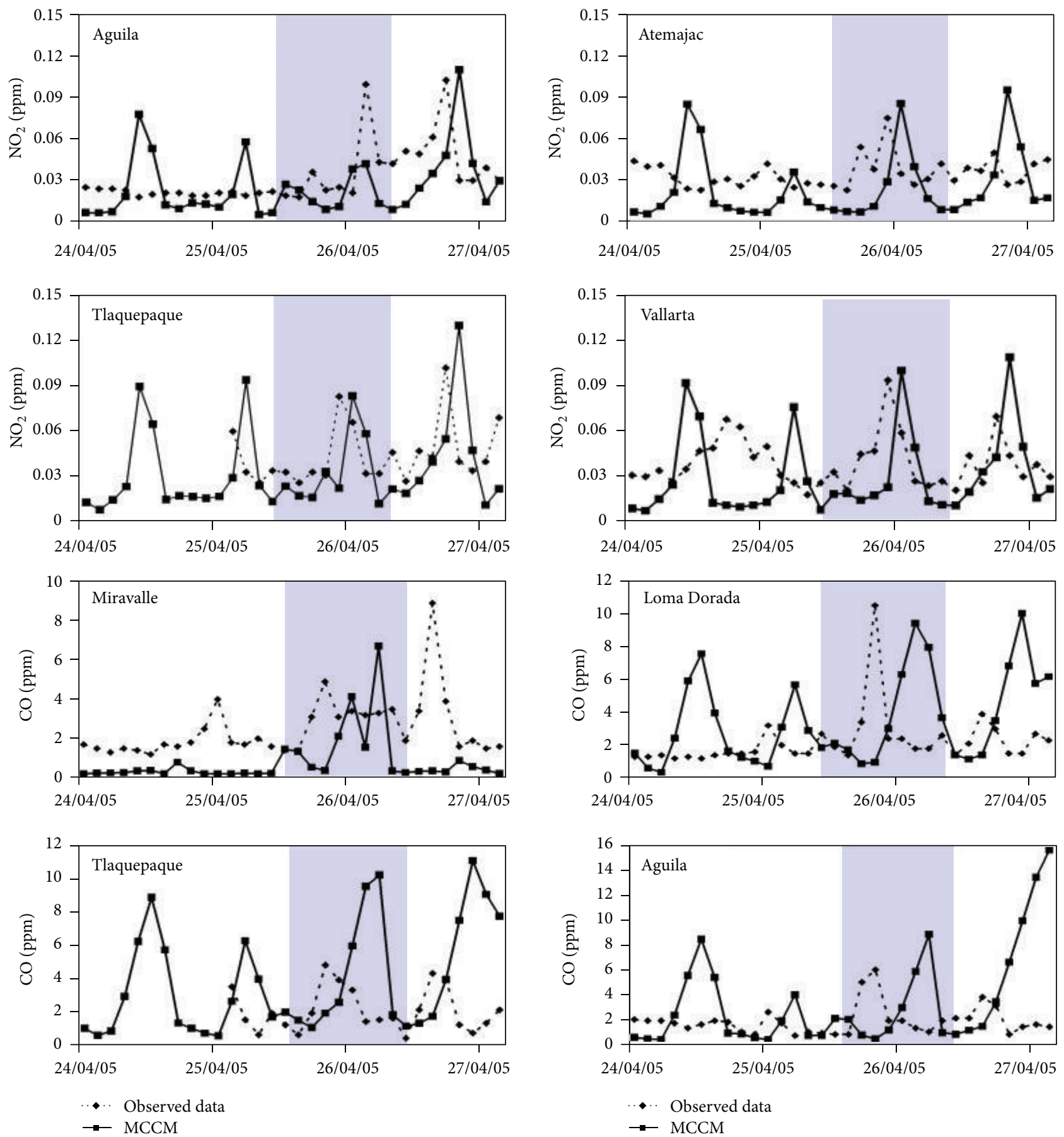

FIGURE 8: Observed and calculated time series of $\mathrm{CO}$ and $\mathrm{NO}_{2}$ at different monitoring stations of the air quality in the metropolitan zone of Guadalajara [33]. The shaded zones indicate the period when the intensity of wildfires was a maximum.

conditions over the urban zone of Guadalajara. Observed and modeled CO, PM10, and $\mathrm{NO}_{2}$ data indicated that aerosol plumes generated by the wildfires increased 3-4 times the concentrations over the MZG. The heat island effect enhances convection over the urban area. Measured and calculated concentrations of pollutants have been compared and satisfactorily reproduced. Data from a network of 7 air quality monitor stations and 3 additional meteorological stations to assess the meteorological conditions were applied. The emitted aerosols dispersed over large areas of the westerncentral part of Mexico. The concentrations and the form of the plume were correctly reproduced. A satellite image of the plume and the calculated plume coincided quite well. The deterioration of the air quality during the period of wildfires events, here documented, should be considered in the fire management planning. 


\section{Conflict of Interests}

The authors declare that there is no conflict of interests regarding the publication of this paper.

\section{References}

[1] J. S. Levine, "Introduction: global biomass burning: Atmospheric, climatic, and biospheric implications," in Global Biomass Burning, Atmospheric, Climatic and Biospheric Implications, J. S. Levine, Ed., pp. 25-30, MIT Press, Cambridge, Mass, USA, 1991.

[2] S. W. Running, "Is global warming causing more, larger wildfires?” Science, vol. 313, no. 5789, pp. 927-928, 2006.

[3] L. Wang, N. Zhang, Z. Liu, Y. Sun, D. Ji, and Y. Wang, "The influence of climate factors, meteorological conditions, and boundary-layer structure on severe haze pollution in the beijingtianjin-hebei region during January 2013," Advances in Meteorology, vol. 2014, Article ID 685971, 14 pages, 2014.

[4] P. Barbosa, A. Camia, J. Kucera et al., "Assessment of forest fire impacts and emissions in the European Union based on the European Forest Fire Information System," Developments in Environmental Science, vol. 8, pp. 197-208, 2008.

[5] M. Lazaridis, M. Latos, V. Aleksandropoulou, O. Hov, A. Papayannis, and K. Tørseth, "Contribution of forest fire emissions to atmospheric pollution in Greece," Air Quality, Atmosphere \& Health, vol. 1, no. 3, pp. 143-158, 2008.

[6] A. H. Bravo, E. R. Sosa, A. P. Sánchez, P. M. Jaimes, and R. M. I. Saavedra, "Impact of wildfires on the air quality of Mexico City, 1992-1999," Environmental Pollution, vol. 117, no. 2, pp. 243-253, 2002.

[7] S. Mukai, M. Yasumoto, and M. Nakata, "Estimation of biomass burning influence on air pollution around Beijing from an aerosol retrieval model," The Scientific World Journal, vol. 2014, Article ID 649648, 10 pages, 2014.

[8] F. Chen, S. Niu, X. Tong, J. Zhao, Y. Sun, and T. He, “The impact of precipitation regimes on forest fires in Yunnan Province, Southwest China," The Scientific World Journal, vol. 2014, Article ID 326782, 9 pages, 2014.

[9] G. R. van der Werf, J. T. Randerson, L. Giglio et al., "Global fire emissions and the contribution of deforestation, savanna, forest, agricultural, and peat fires (1997-2009)," Atmospheric Chemistry and Physics, vol. 10, no. 23, pp. 11707-11735, 2010.

[10] N. E. Clinton, P. Gong, and K. Scott, "Quantification of pollutants emitted from very large wildland fires in Southern California, USA," Atmospheric Environment, vol. 40, no. 20, pp. 3686-3695, 2006.

[11] F. B. Vicente, N. Carbajal, and L. F. P. Martínez, "Estimation of total yearly $\mathrm{CO}_{2}$ emissions by wildfires in Mexico during the Period 1999-2010," Advances in Meteorology, vol. 2014, Article ID 958457, 8 pages, 2014.

[12] J. P. Greenberg, P. R. Zimmerman, L. Heidt, and W. Pollock, "Hydrocarbon and carbon monoxide emissions from biomass burning in Brazil," Journal of Geophysical Research: Atmospheres, vol. 89, no. 1, pp. 1350-1354, 1984.

[13] D. Chang and Y. Song, "Estimates of biomass burning emissions in tropical Asia based on satellite-derived data," Atmospheric Chemistry and Physics, vol. 9, pp. 19599-19640, 2009.

[14] R. Damoah, N. Spichtinger, C. Forster et al., "Around the world in 17 days-Hemispheric-scale transport of forest fire smoke from Russia in May 2003," Atmospheric Chemistry and Physics, vol. 4, no. 5, pp. 1311-1321, 2004.
[15] M. A. Cochrane, "Synergistic interactions between habitat fragmentation and fire in evergreen tropical forests," Conservation Biology, vol. 15, no. 6, pp. 1515-1521, 2001.

[16] H. Asbjornsen and C. G. Hernández, "Impactos de los incendios de 1998 en el bosque mesófilo de montaña de Los Chimalapas, Oaxaca," in Incendios Forestales en México-Métodos de Evaluación, R. L. Villers and J. López, Eds., pp. 125-145, Centro de Ciencias de la Atmósfera, UNAM, Coyoacán, Mexico, 2004.

[17] C. Lauk and K.-H. Erb, "Biomass consumed in anthropogenic vegetation fires: global patterns and processes," Ecological Economics, vol. 69, no. 2, pp. 301-309, 2009.

[18] D. R. Cahoon Jr., B. J. Stocks, J. S. Levine, W. R. Cofer III, and J. M. Pierson, "Satellite analysis of the severe 1987 forest fires in northern China and southeastern Siberia," Journal of Geophysical Research: Atmospheres, vol. 99, no. 9, pp. 1862718638, 1994.

[19] R. J. Yokelson, S. P. Urbanski, E. L. Atlas et al., "Emissions from forest fires near Mexico City," Atmospheric Chemistry and Physics, vol. 7, no. 21, pp. 5569-5584, 2007.

[20] G. A. Grell, J. Dudhia, and D. R. Stauffer, "A description of the fifth-generation Penn State/NCAR mesoscale model (MM5)," NCAR Technical Note NCAR/TN-398+STR, 1994.

[21] J. Dudhia, "Numerical study of convection observed during the winter monsoon experiment using a mesoscale two-dimensional model," Journal of the Atmospheric Sciences, vol. 46, no. 20, pp. 3077-3107, 1989.

[22] P. Schultz, "An explicit cloud physics parameterization for operational numerical weather prediction," Monthly Weather Review, vol. 123, no. 11, pp. 3331-3343, 1995.

[23] E. Kalnay, M. Kanamitsu, R. Kistler et al., "The NCEP/NCAR 40-year reanalysis project," Bulletin of the American Meteorological Society, vol. 77, no. 3, pp. 437-471, 1996.

[24] G. A. Grell, S. Emeis, W. R. Stockwell et al., "Application of a multiscale, coupled MM5/chemistry model to the complex terrain of the VOTALP valley campaign," Atmospheric Environment, vol. 34, no. 9, pp. 1435-1453, 2000.

[25] W. Seiler and P. J. Crutzen, "Estimates of gross and net fluxes of carbon between the biosphere and the atmosphere from biomass burning," Climatic Change, vol. 2, no. 3, pp. 207-247, 1980.

[26] C. Wiedinmyer, B. Quayle, C. Geron et al., "Estimating emissions from fires in North America for air quality modeling," Atmospheric Environment, vol. 40, no. 19, pp. 3419-3432, 2006.

[27] X. Carmona, J. G. F. Garnica, and Á. A. C. Durán, “Análisis comparativo de cargas de combustibles en ecosistemas forestales afectados por incendios," Revista Mexicana de Ciencias Forestales, vol. 2, no. 3, pp. 37-52, 2012.

[28] C. Michel, C. Liousse, J.-M. Grégoire, K. Tansey, G. R. Carmichael, and J.-H. Woo, "Biomass burning emission inventory from burnt area data given by the SPOT-VEGETATION system in the frame of TRACE-P and ACE-Asia campaigns," Journal of Geophysical Research D: Atmospheres, vol. 110, no. 9, pp. 2156-2202, 2005.

[29] L. F. Pineda-Martínez, N. Carbajal, A. Campos-Ramos, A. Aragón-Piña, and A. R. García, "Dispersion of atmospheric coarse particulate matter in the San Luis Potosí, Mexico, urban area," Atmosfera, vol. 27, no. 1, pp. 5-19, 2014.

[30] CONABIO, Programa para la Detección de Puntos de Calor Mediante Técnicas de Percepción Remota. Monitoreo de Puntos de Calor, CONABIO, México City, Mexico, 2010, http://www .conabio.gob.mx/conocimiento/puntos_calor/doctos/puntos_ calor.html. 
[31] E. Jauregui, L. Godinez, and F. Cruz, "Aspects of heat-island development in Guadalajara, Mexico," Atmospheric Environment. Part B, Urban Atmosphere, vol. 26, no. 3, pp. 391-396, 1992.

[32] I. E. Tereshchenko and A. E. Filonov, "Air temperature fluctuations in Guadalajara, Mexico, from 1926 to 1994 in relation to urban growth," International Journal of Climatology, vol. 21, no. 4, pp. 283-494, 2001.

[33] Sistema Nacional de Información de la Calidad del Aire (SINAICA), Instituto Nacional de Ecologia, Mexico, 2008, http://sinaica.ine.gob.mx.

[34] C. A. Pio, M. Legrand, C. A. Alves et al., "Chemical composition of atmospheric aerosols during the 2003 summer intense forest fire period," Atmospheric Environment, vol. 42, no. 32, pp. 7530 7543, 2008.

[35] Satellite Aqua (NASA), http://rapidfire.sci.gsfc.nasa.gov/gallery/ ?2005116-0426/Mexico.A2005116.1945.250m.jpg. 

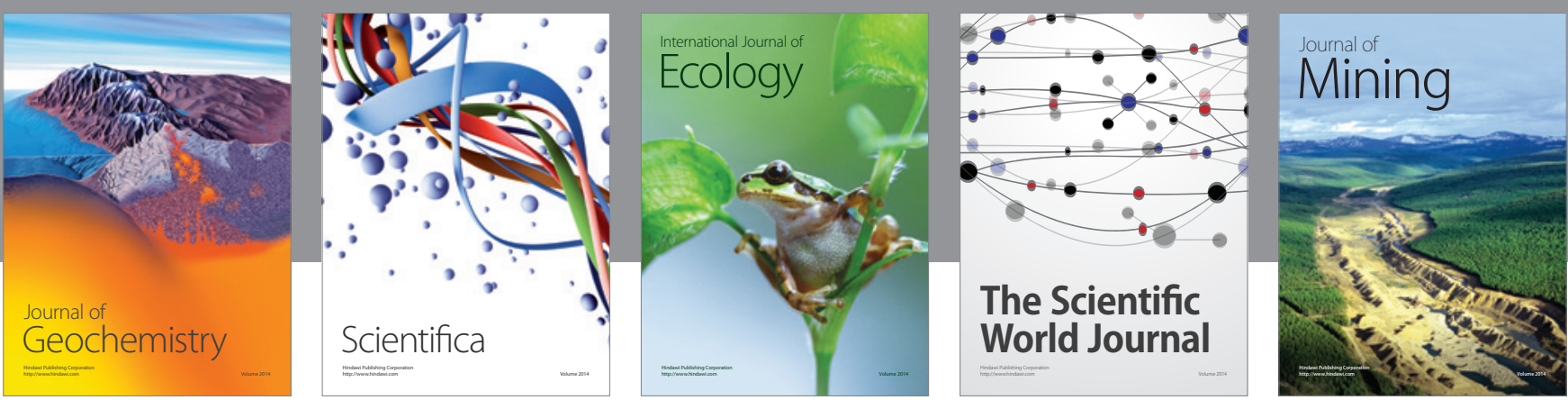

The Scientific World Journal
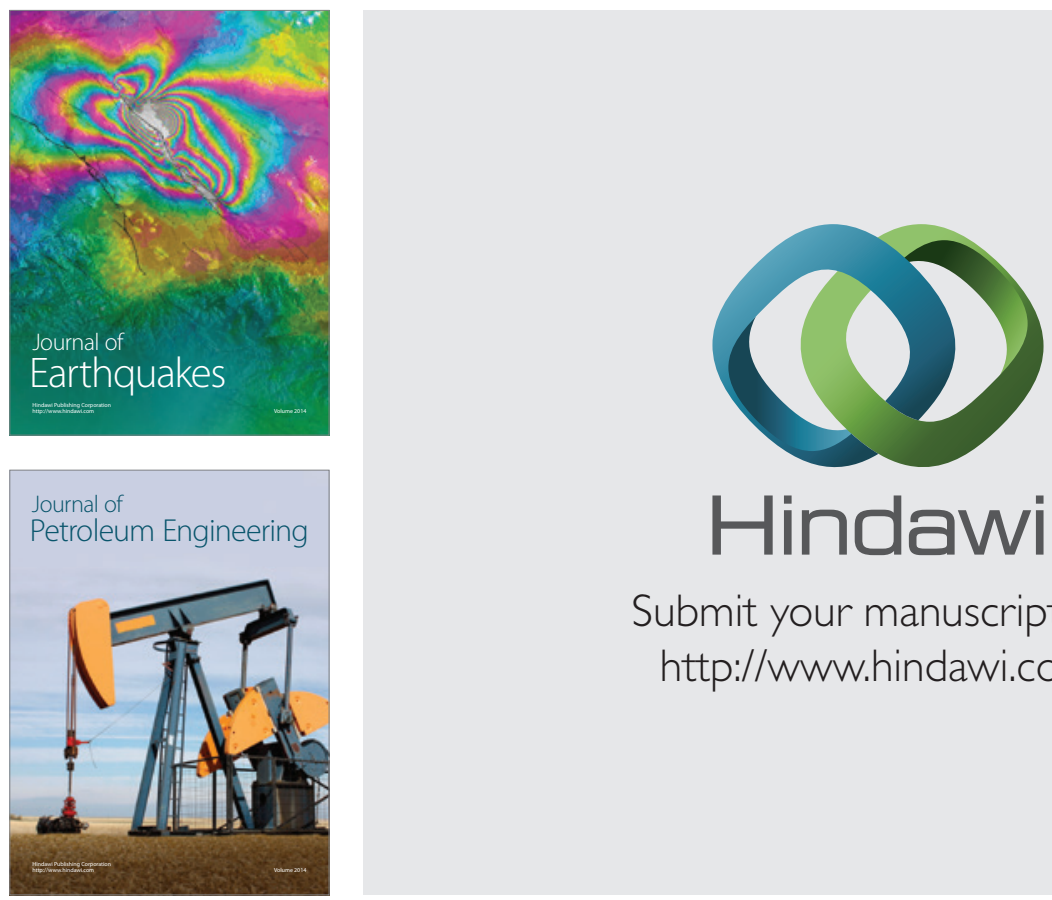

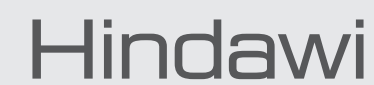

Submit your manuscripts at

http://www.hindawi.com
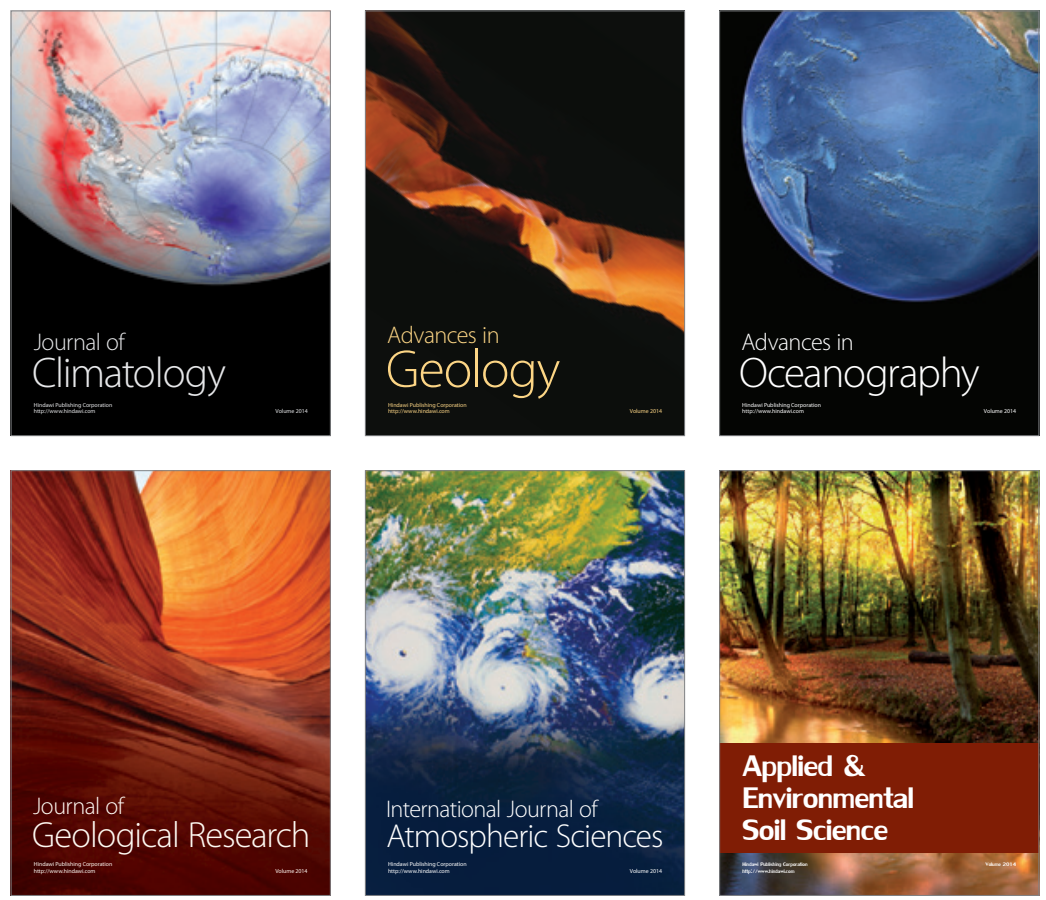
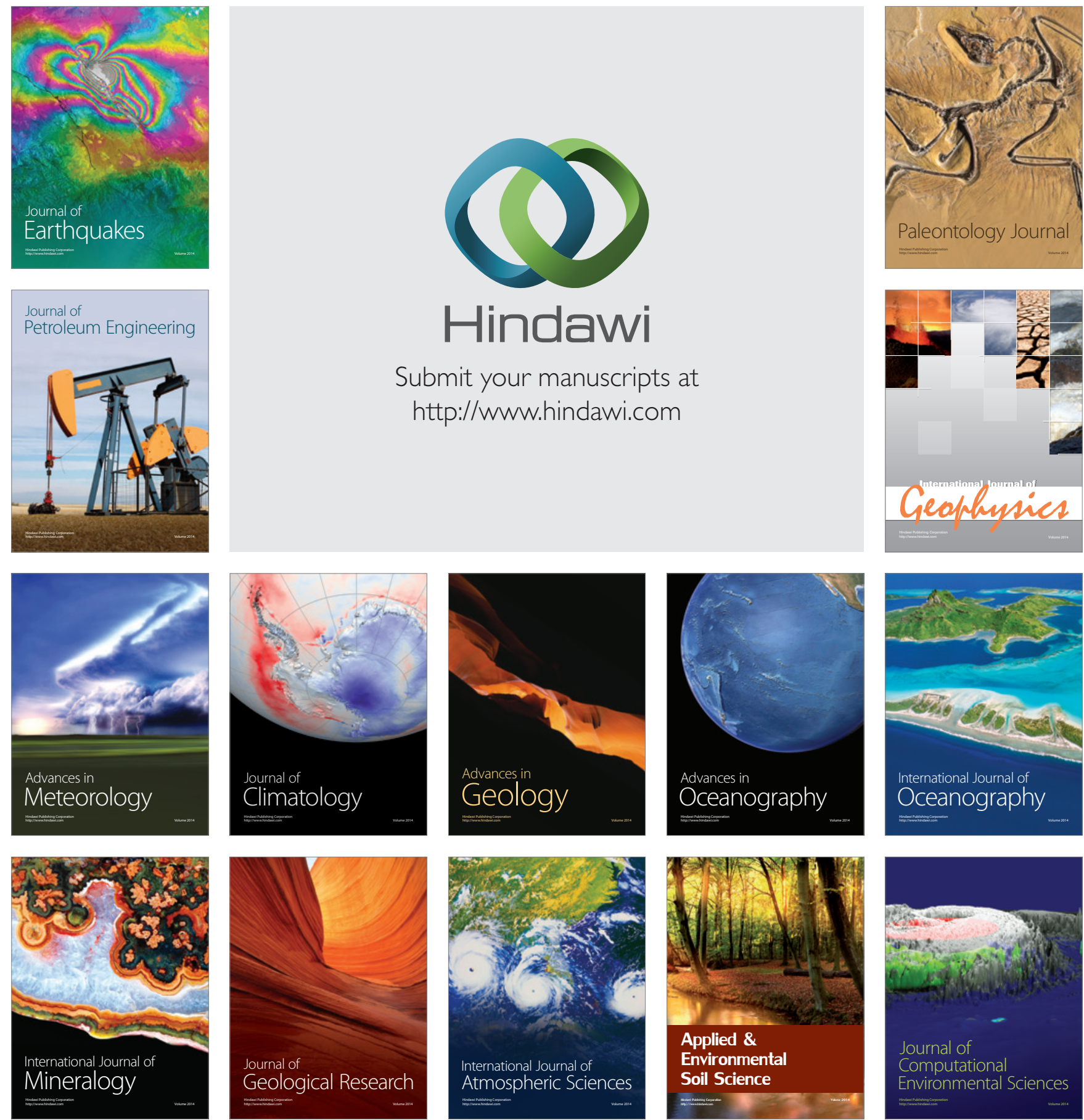